\title{
Anticancer activity of taraxerol acetate in human glioblastoma cells and a mouse xenograft model via induction of autophagy and apoptotic cell death, cell cycle arrest and inhibition of cell migration
}

\author{
JING-FANG HONG ${ }^{1 *}$, YING-FANG SONG ${ }^{2 *}$, ZHENG LIU ${ }^{1}$, \\ ZHAO-CONG ZHENG ${ }^{1}$, HONG-JIE CHEN ${ }^{1}$ and SHOU-SEN WANG ${ }^{1}$
}

Departments of ${ }^{1}$ Neurosurgery and ${ }^{2}$ Pulmonary and Critical Care Medicine, Fuzhou General Hospital of
Nanjing Military Command, Dongfang Hospital, Xiamen University,
Fuzhou, Fujian 350025, P.R. China

Received June 10, 2015; Accepted January 22,2016

\begin{abstract}
The aim of the present study was to investigate the in vitro and in vivo anticancer and apoptotic effects of taraxerol acetate in U87 human glioblastoma cells. The effects on cell cycle phase distribution, cell cycle-associated proteins, autophagy, DNA fragmentation and cell migration were assessed. Cell viability was determined using the MTT assay, and phase contrast and fluorescence microscopy was utilized to determine the viability and apoptotic morphologieal features of the U87 cells. Flow cytometry using propidium iodide and Annexin V-fluorescein isothiocyanate demonstrated the effect of taraxerol acetate on the cell cycle phase distribution and apoptosis induction. Western blot analysis was performed to investigate the effect of the taraxerol acetate on cell cycle-associated proteins and autophagy-linked LC3B-II proteins. The results demonstrated that taraxerol acetate induced dose- and time-dependent cytotoxic effects in the U87 cells. Apoptotic induction following taraxerol acetate treatment was observed and the percentage of apoptotic cells increased from $7.3 \%$ in the control cells, to 16.1, 44.1 and $76.7 \%$ in the 10,50 and $150 \mu \mathrm{M}$ taraxerol acetate-treated cells, respectively. Furthermore, taraxerol acetate treatment led to sub- $\mathrm{G}_{1}$ cell cycle arrest with a corresponding decrease in the number of S-phase cells. DNA fragments were observed as a result of the gel electrophoresis
\end{abstract}

Correspondence to: Professor Shou-Sen Wang, Department of Neurosurgery, Fuzhou General Hospital of Nanjing Military Command, Dongfang Hospital, Xiamen University, 156 West Second Ring Road, Fuzhou, Fujian 350025, P.R. China

E-mail: shousenss@hotmail.com

${ }^{*}$ Contributed equally

Key words: taraxerol acetate, apoptosis, autophagy, cytotoxicity, cell cycle experiment following taraxerol acetate treatment. To investigate the inhibitory effects of taraxerol acetate on the migration of U87 cell, a wound healing assay was conducted. The number of cells that migrated to the scratched area decreased significantly following treatment with taraxerol acetate. In addition, taraxerol acetate inhibited tumor growth in a mouse xenograft model. Administration of 0.25 and $0.75 \mu \mathrm{g} / \mathrm{g}$ taraxerol acetate reduced the tumor weight from $1.2 \mathrm{~g}$ in the phosphate-buffered saline (PBS)-treated group (control) to 0.81 and $0.42 \mathrm{~g}$, respectively. Similarly, 0.25 and $0.75 \mu \mathrm{g} / \mathrm{g}$ taraxerol acetate injection reduced the tumor volume from $1.3 \mathrm{~cm}^{3}$ in the PBS-treated group (control) to 0.67 and $0.25 \mathrm{~cm}^{3}$, respectively.

\section{Introduction}

Glioblastoma multiforme (GBM) is the most common type of central nervous system cancer in adults. Aggressive behavior is characteristic of this type of cancer and it is associated with a poor prognosis. Despite recent advances in treatment options, such as surgery, chemotherapy and radiotherapy, patients with glioblastoma demonstrate a low median survival time of $<2$ years $(1,2)$. The incidence of primary brain tumor has markedly increased in the past two decades, and is expected to increase further due to higher life expectancies. GBM is the most malignant form of brain tumor in adults and is classified as a grade IV astrocytoma by the World Health Organization (WHO). The 2007 WHO classification of tumors of the central nervous system divides glioma into grades I-IV, in which grades I and II are classified as low grade, and grades III and IV are defined as high grade (known as malignant glioma) (3). GBM is associated with increased mortality rates; these are associated with genetic disorders such as neurofibromatosis and Li Fraumeni syndrome, and previous radiation therapy. GBM may develop at any age and has a peak incidence after $>50$ years of life (4). The incidence rate of cancer in China is $1-4 / 100,000$, with GBM being the most common type of primary brain tumor (5). Symptoms include headaches, epilepsy, dysphasia and cognitive change, which occur due to the extensive damage to 
healthy brain cells and tumor invasion (6). The treatment options for GBM are surgical removal of the local lesion, followed by adjuvant radio- and chemotherapy $(7,8)$. Despite these advanced treatment strategies, the prognosis of GBM patients remains poor, predominantly due to high rates of recurrence. This is further compounded by the resistance of cancer cells to radiation and chemotherapy. Novel and efficient treatment options, which are less susceptible to adapting resistance and that have low toxicity profiles for healthy cells, are required.

Natural products derived from plants are currently being considered as potential chemopreventive and chemotherapeutic agents. During preclinical and clinical trials certain natural products demonstrated promising results for cancer prevention and treatment (9). Previous studies demonstrated the anticancer properties of natural products and plant extracts against various types of human cancer (10-13). Furthermore, there is a specific and increasing interest in the anticancer properties of natural products for the treatment of glioblastoma (14-17). To the best of our knowledge, the anticancer potential of taraxerol acetate against human glioblastoma cells has not been investigated. The aim of the current study was to demonstrate the anticancer properties of taraxerol acetate in the U87 human primary glioblastoma cell line, and investigate its effect on induction of autophagy and apoptosis, cell cycle arrest, cell migration and invasion.

\section{Materials and methods}

Chemicals and reagents. Taraxerol acetate (purity $\geq 98 \%$ ) ethidium bromide (EB), the Annexin V-flurescein isothiocyanate (FITC)/propidium iodide (PI) apoptosis detection kit (APOAF), acridine orange (AO) dye and MTT were obtained from Sigma-Aldrich (St. Louis, MO USA). Dulbecco's modified Eagle's medium (DMEM), fetal bovine serum (FBS), penicillin, streptomycin, trypsin and phosphate-buffered saline (PBS), supplemented with calcium chloride and magnesium chloride, were obtained from Hangzhou Sijiqing Biological Engineering Materials Co., Ltd. (Hangzhou, China). Primary monoclonal rabbit antibodies against p21 (dilution, 1:1,000; \#2947), cyclin B (dilution, 1:1,000; \#12231), cyclin D (dilution, 1:1,000; \#92G2), cyclin-dependent kinase (CDK) 2 (\#2546), CDK4 (\#12790) and CDK6 (\#13331) (alldilution, 1:1,000) were purchased from Cell Signaling Technology, Inc. (Danvers, MA, USA). Microtubule associated protein light chain 3B (LC3B; dilution, 1:500; rabbit polyclonal; \#L8918) was purchased from Sigma-Aldrich, and mouse monoclonal $\alpha$-tubulin (dilution, 1:1,000; \#sc-5286) and GAPDH (dilution, 1:1,000; sc-365062) primary antibodies were purchased from Santa Cruz Biotechnology, Inc. (Dallas, TX, USA), respectively. All other chemicals and solvents used were of the highest purity grade.

Cell culture. The U87 human glioblastoma cell line was purchased from the Shanghai Institute of Cell Resource Center of Life Science (Shanghai, China). U87 cells were maintained in DMEM supplemented with $10 \%$ (v/v) FBS under a humidified atmosphere of $5 \% \mathrm{CO}_{2}$ at $37^{\circ} \mathrm{C}$. The medium was replaced every 2 days and the cells were subcultured every 4 days.
Cell proliferation assay. The effects of taraxerol acetate on U87 cell proliferation were determined using the MTT assay. Briefly, $1 \times 10^{5}$ cells were seeded into a 96-well plate and incubated for $5-7 \mathrm{~h}$ at $37^{\circ} \mathrm{C}$ for attachment. Following treatment with taraxerol acetate $(0,5,10,25,50,100$ and $150 \mu \mathrm{M})$ for $48 \mathrm{~h}$, MTT solution (10 $\mu \mathrm{l} ; 5 \mathrm{mg} / \mathrm{ml}$ in PBS solution) was added to the cells for $4 \mathrm{~h}$ at $37^{\circ} \mathrm{C}$. The formazan crystals were solubilized with $150 \mu \mathrm{l}$ dimethyl sulfoxide and the absorbance was measured on a microplate reader (ELx800; Bio-tek Instruments, Inc., Winooski, VT, USA) at a wavelength of $490 \mathrm{~nm}$. The effects of taraxerol acetate on cell viability were calculated as an inhibition ratio (I\%) using the following formula: $\mathrm{I} \%=\left[\mathrm{OD}_{490}\right.$ (control) $-\mathrm{OD}_{490}$ (treated) $] / \mathrm{OD}_{490}$ (control) $\mathrm{x} 100$. Where $\mathrm{OD}_{490}$ is the optical density at $490 \mathrm{~nm}$.

Phase contrast and fluorescence microscopy. U87 cells were plated into 6-well plates at a density of $1 \times 10^{5}$ cells $/ \mathrm{ml}$ and cultured for $24 \mathrm{~h}$ to enable cell attachment to the surface of the plates. Cells were treated with taraxerol acetate $(0,10$, 50 or $150 \mu \mathrm{M}$ ) for $48 \mathrm{~h}$ and examined using a phase contrast microscope (Eelipse TE2000-E, Nikon Corporation, Tokyo, Japan), Images were capturec.

The same seeding protocol and treatment was repeated to conduct a staining protocol. Briefly, cells were washed twice with PBS following treatment incubation for $30 \mathrm{~min}$ at $37^{\circ} \mathrm{C}$ and $\mathrm{AO} / \mathrm{EB}$ solution $(10 \mu \mathrm{g} / \mathrm{ml})$ was added to the wells. Images of the cells were captured using a fluorescence microscope (FSX100; Olympus Corporation, Tokyo, Japan).

Quantification of apoptotic cell death via Annexin V-FITC/PI assay. Cells were treated with taraxerol acetate $(0,10,50$ and $150 \mu \mathrm{M}$ ) and stained with $0.5 \mathrm{ml} \mathrm{PI}$ and Annexin V-FITC according to the manufacturer's instructions. Subsequent to staining, the percentages of viable, apoptotic and necrotic cells were analyzed by flow cytometry using the BD FACSCalibur flow cytometer (BD Biosciences, San Jose, CA, USA), and data were analyzed with the CellQuest software, version 3.3 (BD Biosciences).

Effect of taraxerol acetate on cell cycle progression. Flow cytometry was utilized to assess the effect of taraxerol acetate, and data were analyzed using the FACSCalibur platform equipped with CellQuest software. The ModFit LT cell cycle analysis software (version 4.0; Verity Software House, Inc., Topsham, ME, USA) was used to determine the percentage of cells in the various phases of the cell cycle. Briefly, $1 \times 10^{5} \mathrm{U} 87$ cells were treated with taraxerol acetate $(0,10,50$ and $150 \mu \mathrm{M})$ for $48 \mathrm{~h}$. Cells were then collected, washed with ice-cold PBS twice, fixed with $70 \%$ alcohol at $4^{\circ} \mathrm{C}$ for $12 \mathrm{~h}$, and stained with PI in the presence of $3 \%$ RNAase A (Sigma-Aldrich) at $37^{\circ} \mathrm{C}$ for $20 \mathrm{~min}$, prior to analysis with flow cytometry.

DNA fragmentation analysis. U87 cells were seeded in a 100-mm cell culture dish for $24 \mathrm{~h}$, and treated with 0,10 , 50 and $150 \mu \mathrm{M}$ taraxerol acetate for $48 \mathrm{~h}$. The cells were harvested and washed with PBS, and the pellets were lysed with $400 \mu$ l DNA lysis buffer (2\% NP-40, 20 mM EDTA and $40 \mathrm{mM}$ Tris-HCl; Sigma-Aldrich) for $30 \mathrm{~min}$. Subsequent to centrifugation at $6,600 \mathrm{x}$ g for $5 \mathrm{~min}$, the supernatants were prepared in an equal volume of $1.5 \%$ sodium-dodecyl sulphate 
A<smiles>CC(=O)OC1CCC2(C)C3=CC[C@]4(C)CCC(C)(C)C[C@H]4[C@]3(C)CC[C@@H]2C1(C)C</smiles>

B

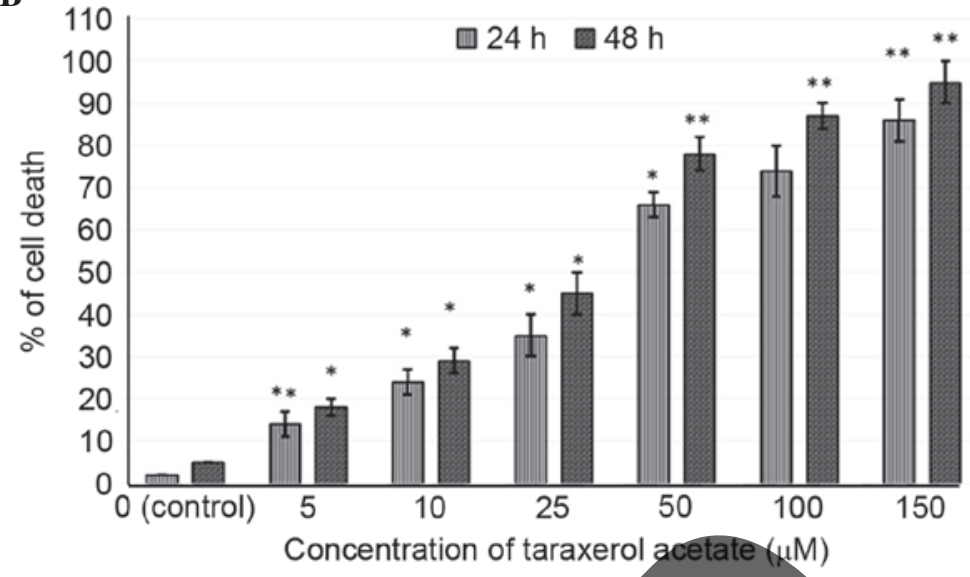

Figure 1. (A) Chemical structure of taraxerol acetate. (B) Cytotoxic effect of theaflavin-3-gallate in U87 human glioblastoma cells. Data are presented as the mean \pm standard deviation $(n=3) .{ }^{*} \mathrm{P}<0.05$ and ${ }^{* *} \mathrm{P}<0.01$ vs. the control.

(SDS; Siamg-Aldrich), incubated with $2.5 \mathrm{mg} / \mathrm{ml}$ RNase A at $60^{\circ} \mathrm{C}$ for $2 \mathrm{~h}$ followed by digestion with $2.5 \mathrm{mg} / \mathrm{ml}$ proteinase $\mathrm{K}$ (Sigma-Aldrich) for $2 \mathrm{~h}$ at $20^{\circ} \mathrm{C}$. Following the addition of 0.5 volumes of $10 \mathrm{M}$ ammonium acetate (Sigma-Aldrich), the DNA was precipitated with cold ethanol and collected by centrifugation at $6,600 \times \mathrm{g}$ for $20 \mathrm{~min}$. DNA was then dissolved in gel loading buffer (Sigma-Aldrich), separated by electrophoresis in $1.5 \%$ agarose gel $(1 \mathrm{~h}$ at $100 \mathrm{~V})$ and visualized under ultraviolet light, following EB staining.

Cell migration (wound healing) assay. This assay was performed as previously described (17). Briefly, U87 cells $\left(1 \times 10^{5}\right.$ cells $\left./ \mathrm{ml}\right)$ were seeded into a 6 -well plate and incubated at $37^{\circ} \mathrm{C}$ for $24 \mathrm{~h}$ until a $95 \%$ confluent monolayer of cells was attained. Following $12 \mathrm{~h}$ of starvation, a 100 -mI pipette tip was used to create a straight cell-free wound. Each well was washed three times with PBS to remove any cell debris, and then subjected to taraxerol acetate $(0,10,50$ and $150 \mu \mathrm{M})$ in DMEM. Subsequent to $48 \mathrm{~h}$ of incubation at $27^{\circ} \mathrm{C}$, the cells were fixed and stained with $5 \%$ ethanol containing $0.3 \%$ crystal violet powder (Sigma-Aldrich) for $30 \mathrm{~min}$, and images of randomly selected fields were captured under an IX71 inverted research microscope (Olympus Corporation). The number of cells that migrated into the scratched area were counted and the lengths of wound were determined by Image J software, version 1.46 (http://imagej.nih.gov/ij/)

Western blot assay. The assay was performed as previously described (18). Briefly, total protein was extracted from the U87 cells and concentration was measured using the bicinchoninic acid protein assay kit (Thermo Fisher Scientific, Inc., Waltham, MA, USA ) according to the manufacturer's instructions. Protein samples $(100 \mu \mathrm{g})$ were run on an SDS-polyacrylamide gel $(3 \mathrm{~h}$ at $70 \mathrm{~V})$ and the proteins were then transferred to nitrocellulose membranes (Sigma-Aldrich). The membranes were blocked with $5 \%$ bovine serum albumin (Sigma-Aldrich) for $2 \mathrm{~h}$ at room temperature and incubated with primary antibodies overnight at $4^{\circ} \mathrm{C}$. This was followed by incubation with relevant secondary antibodies $(1: 10,000$; Abcam, Cambridge, UK) for $1 \mathrm{~h}$ at room temperature. The bands were visualized using a ChemiDoc MP Imaging System
(Bio-Rad Laboratories, Inc. (model 1708280; Hercules, CA, USA).

Animals.The effects of taraxerol acetate on tumor development vere investigated using a nude mouse model. The study was approved by the Institutional Animal Care and Use Committee of Fuzhou General Hospital of Nanjing Military Command (Fujian, China).Female BALB/c nude mice (age, 8 weeks; weight, $20 \mathrm{~g}$ ) were purchased from the Shanghai Laboratory Animal Center Laboratory Animal Co., Ltd. (Shanghai, China), and all mice were provided with water and food ad libitum, in a pathogen free environment, under a 12-h light/dark cycle in an animal care facility, according to animal welfare regulations and protocols approved by the Institutional Animal Care and Use Committee of Fuzhou General Hospital of Nanjing Military Command. The U87 cells ( $1 \times 10^{5}$ cells/mouse) were subcutaneously injected into the right rear flank of each mouse to generate the tumor. Following tumor generation, mice were divided into three groups $(n=5)$ and treated once orally with 1X PBS (control), 0.25 or $0.75 \mu \mathrm{g} / \mathrm{g}$ taraxerol acetate (injected intraperitoneally). Mice were sacrificed after 24 days by cervical dislocation, and the tumor weight and volume were assessed. Tumor length and width were measured using a caliper and the tumor volume was calculated using the following formula: Tumor volume $=$ length $\mathrm{x}$ width $\mathrm{x} 0.5$ width.

Statistical analysis. The differences among the control and treatment groups were analyzed using Student's t-test and SPSS software, version 17.0 (SPSS, Inc., Chicago, IL, USA). Data are expressed as the mean \pm standard deviation $(n=3)$. $\mathrm{P}<0.05$ was considered to indicate a statistically significant difference.

\section{Results}

Effect of taraxerol acetate on the proliferation of U87 cells. Taraxerol acetate is a triterpene derivative existing in numerous plant species and its chemical structure is demonstrated in Fig. 1A. The anticancer activity of taraxerol acetate on U87 cells was assessed by MTT assay. The results demonstrated that taraxerol acetate had potent antiproliferative effects on the U87 cells, and exhibited dose- and time-dependent growth 

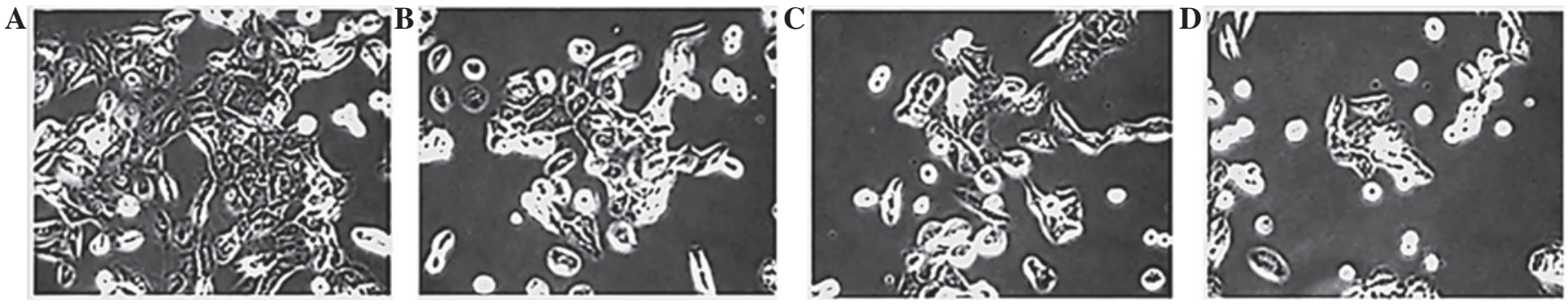

Figure 2. Phase contrast microscopic images to demonstrate the effect of taraxerol acetate treatment on the viability of U87 glioblastoma cells. (A) Untreated (control) U87 cells. (B) 10, (C) 50 and (D) $150 \mu \mathrm{M}$ taraxerol-treated cells. Magnification, x400.
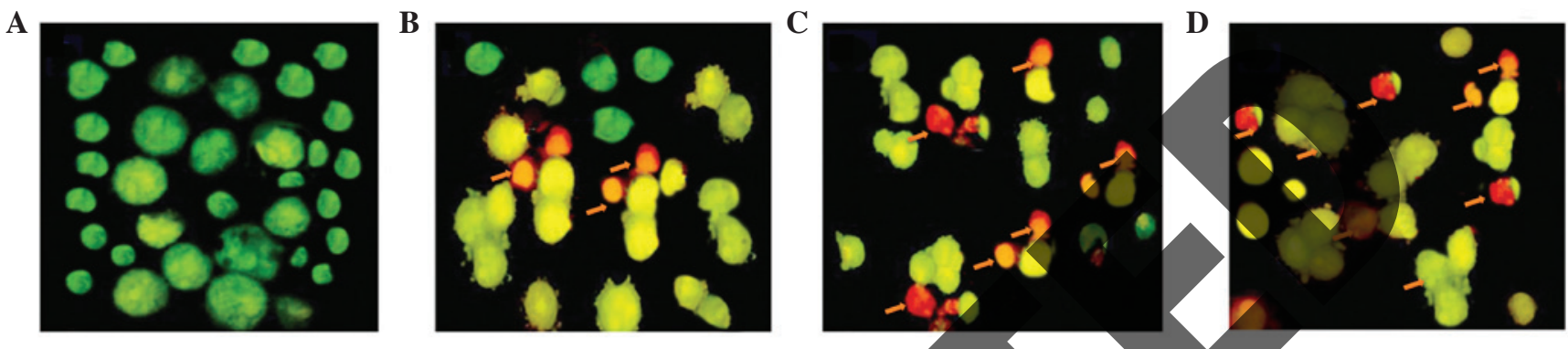

Figure 3. Visualization of apoptotic morphological changes induced by taraxerol acetate in U87 glioblastoma cells using acridine orange/ethidium bromide staining. (A) Untreated cells (control) and cells treated with (B) 10, (C) 50 and (D) $150 \mu \mathrm{M}$ taraxerol. The orange arrows indicate apoptotic cells.

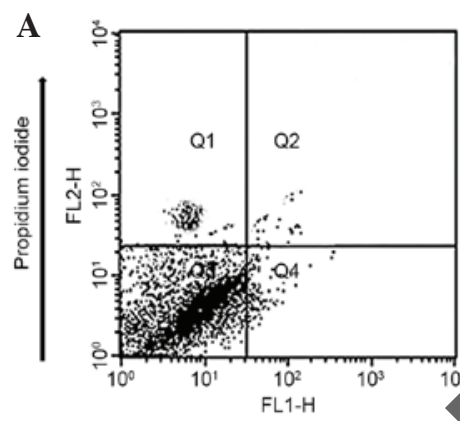

B

B
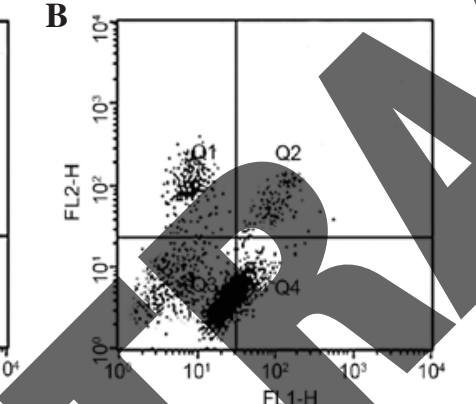
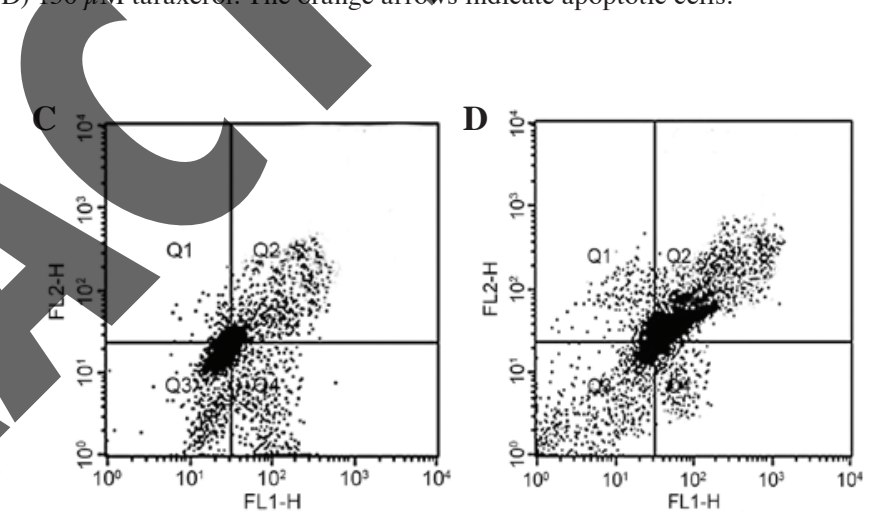

Figure 4. Effect of taraxerolacetate on U87 cell apoptosis. Cells were treated with (A) 0 , (B) 10 , (C) 50 and (D) $150 \mu \mathrm{M}$ taraxerol acetate for 48 h. The Annexin V-fluorescein isothiocyanate-propidium iodide assay and flow cytometry were utilized to quantify apoptosis. The quadrants, Q1-4 represent necrotic, late apoptotic, viable and early apoptotic cells, respectively.

inhibitory effects against these cells (Fig. 1B). Furthermore, the half maximal inhibitory concentration value of taraxerol acetate was 34.2 and $28.4 \mu \mathrm{M}$, at 24 and $48 \mathrm{~h}$, respectively.

Morphological analysis of the U87 cells using phase contrast and fluorescence microscopy. The morphological alterations of untreated and taraxerol acetate-treated cells were examined under a phase contrast microscope. Compared with the control cells, the cells treated with 10,50 and $150 \mu \mathrm{M}$ taraxerol acetate demonstrated a significant reduction in cell viability (Fig. 2). The untreated U87 cells appeared in tightly packed and organized multilayers, compared with the taraxerol acetate-treated cells, which were rounded and shrunken, disconnected from each other or were floating in the medium.

Furthermore, AO and EB double staining was performed in the U87 cells to observe cell apoptosis, using a fluorescence microscope. As demonstrated in Fig. 3A, living cells (control) had large green nuclei, demonstrating that their cell membranes remained undamaged. However, upon treatment with 10 , 50 or $150 \mu \mathrm{M}$ taraxerol acetate, the number of cells with large green nuclei markedly reduced (Fig. 3B-D). At a concentration of $150 \mu \mathrm{M}$ taraxerol acetate, nearly all cells demonstrated signs of nuclear condensation and apoptotic body formation (Fig. 3D).

Apoptosis/necrosis evaluation and quantification using the Annexin V-FITC/PI assay. U87 cells were treated with $0,10,50$ and $150 \mu \mathrm{M}$ taraxerol acetate for $48 \mathrm{~h}$, and the Annexin V-FITC/PI staining was used to detect apoptosis. Compared with the untreated control cells (Fig. 4A), taraxerol acetate induced early and late apoptosis in a dose-dependent manner (Fig. 4B-D). The quadrants Q1-4 represent necrotic, late apoptotic, viable and early apoptotic cells, respectively. The percentage of the apoptotic cells increased from $7.3 \%$ in the control cells (Fig. 4A) to 16.1, 44.1 and $76.7 \%$ in the 10 (Fig. 4B), 50 (Fig. 4C) and $150 \mu \mathrm{M}$ (Fig. 4D) taraxerol acetate-treated cells, respectively. 
A
C
C

$\mathrm{C}$
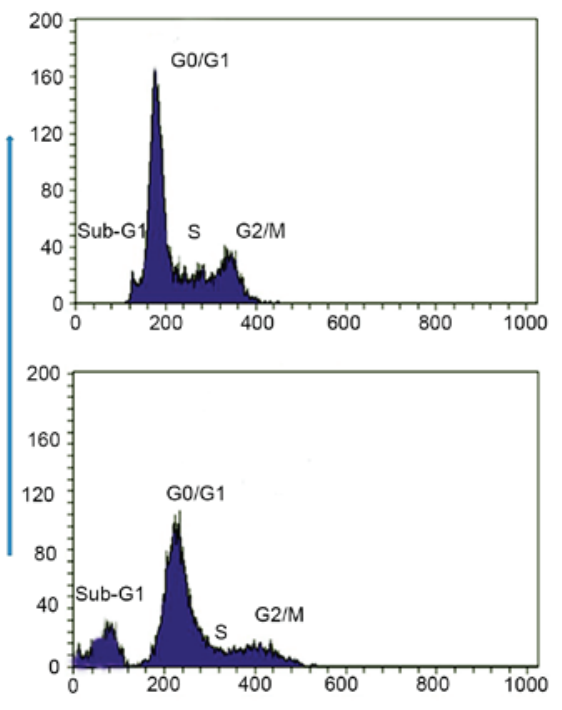

B

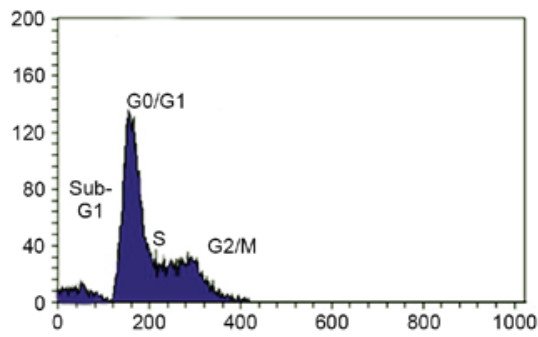

D

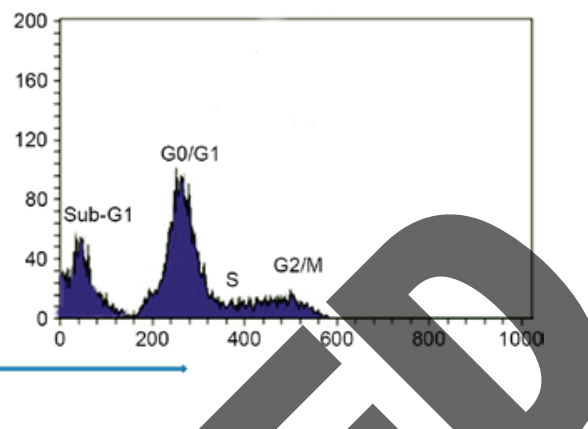

Figure 5. Effect of taraxerol acetate on the cell cycle phase distribution of U87 cells. (A) Control, and cells treated with (B) 10 , (C) 50 and (D) $150 \mu \mathrm{M} \mathrm{taraxerol} \mathrm{acetate.}$ Taraxerol acetate treatment led to a gradual increase in the sub- $\mathrm{G}_{1}$ (apoptotic) cell population with a corresponding reduction in $\mathrm{S}$-phase cell number.

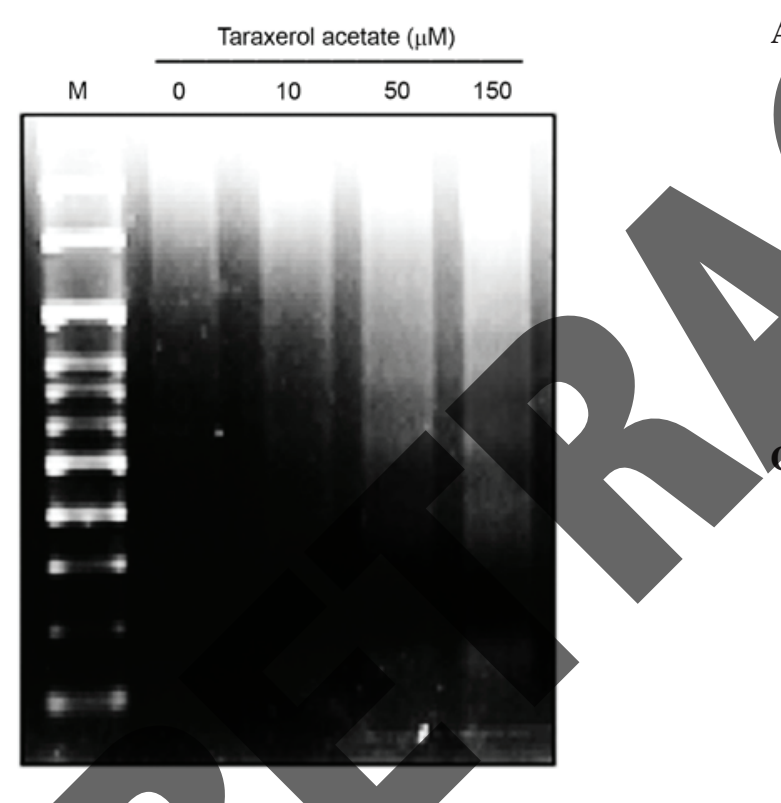

Figure 6. Taraxerol acetate induces DNA fragmentation in U87 cells. The cells were treated with $0,10,50$ and $150 \mu \mathrm{M}$ for $48 \mathrm{~h}$. Harvested and fragmented DNA was extracted and analyzed by $1.5 \%$ garose gel electrophoresis.

Effect of taraxerol acetate on cell cycle progression and DNA fragmentation in the U87 cells. To investigate whether taraxerol acetate induces cell cycle disorders in U87 cells, flow cytometry analysis with PI as a staining agent was conducted subsequent to taraxerol acetate treatment. The results demonstrated that the cell cycle distribution changed with the increasing doses of taraxerol acetate (Fig. 5). The percentage of cells in the sub- $\mathrm{G}_{1}$ phase increased gradually from $2.4 \%$ in the untreated control to 18.6 , 33.21 and $48.6 \%$ following 10,50 and $150 \mu \mathrm{M}$ taraxerol acetate treatment, respectively (Fig. 5). The percentage of cells in the S-phase decreased from $33.15 \%$ in untreated cells to $27.21,16.21$ and $12.9 \%$ following 10,50 and $150 \mu \mathrm{M}$ taraxerol acetate treatment, respectively (Fig. 5). In addition, taraxerol acetate treatment induced dose-dependent DNA fragmentation ladders in U87 cells. This DNA fragmentation is a hallmark of apoptosis (Fig. 6).

Taraxerol acetate inhibited cancer cell migration in U87 cells. The effect of taraxerol acetate on the migration of U87 cells was assessed using an in vitro wound healing assay. The confluent cells were scratched and then subjected to taraxerol acetate treatment for $48 \mathrm{~h}$. An image was captured and the percentage of cells that had migrated into the scratched area was calculated. As demonstrated in Fig. 7, taraxerol acetate led to a marked and dose-dependent reduction in the number of cells migrating into the scratched area. 


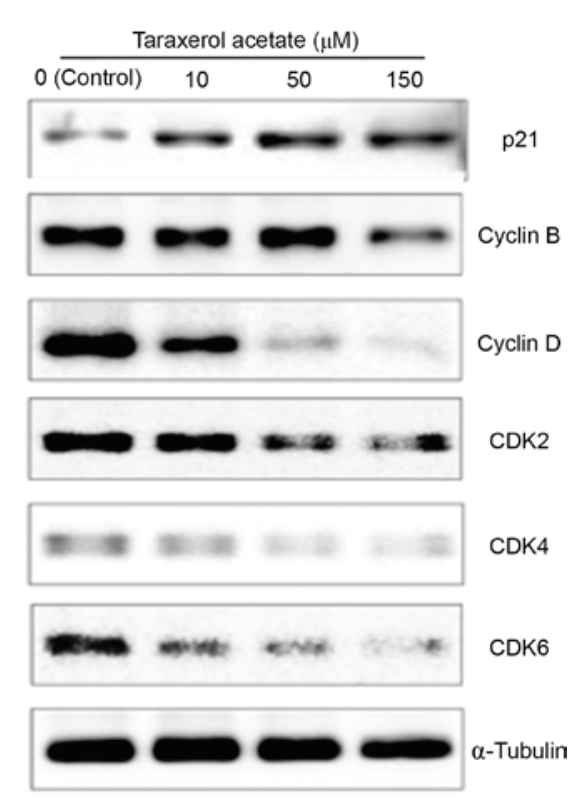

Figure 8. Effect of taraxerol acetate on the expression levels of cell cycle-associated proteins in U87 human glioma cells. The band intensities of control and treated cells were measured by western blotting. $\mathrm{CDK}$, cyclin-dependent kinase.

A

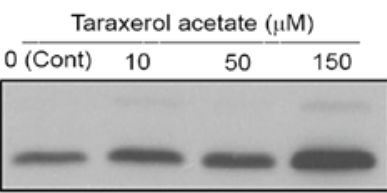
LC3B-II

B
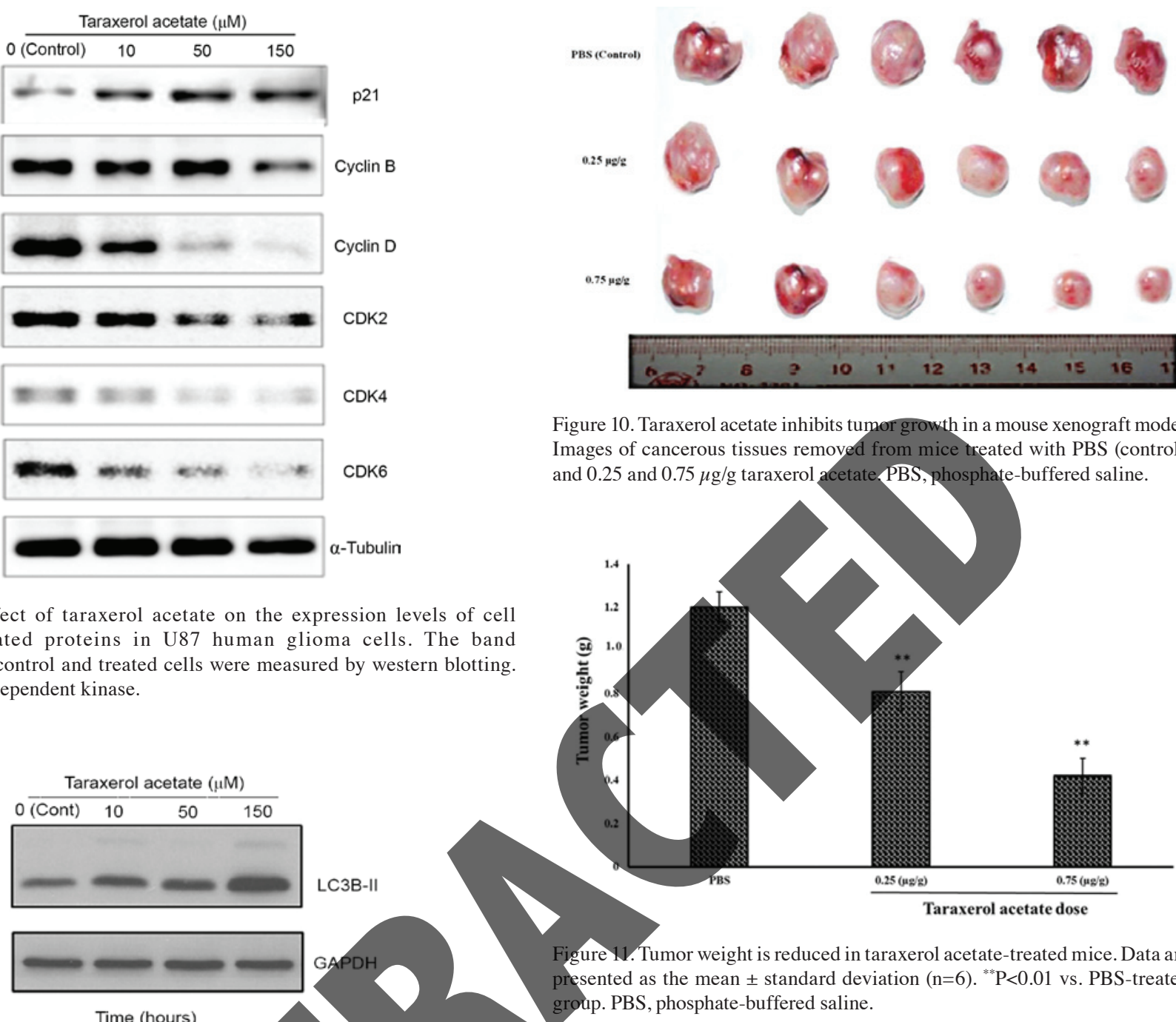

Figure 10. Taraxerol acetate inhibits tumor growth in a mouse xenograft model. Images of cancerous tissues remoyed from mice treated with PBS (control), and 0.25 and $0.75 \mu \mathrm{g} / \mathrm{g}$ taraxerol acetate $\mathrm{PBS}$, phosphate-buffered saline.

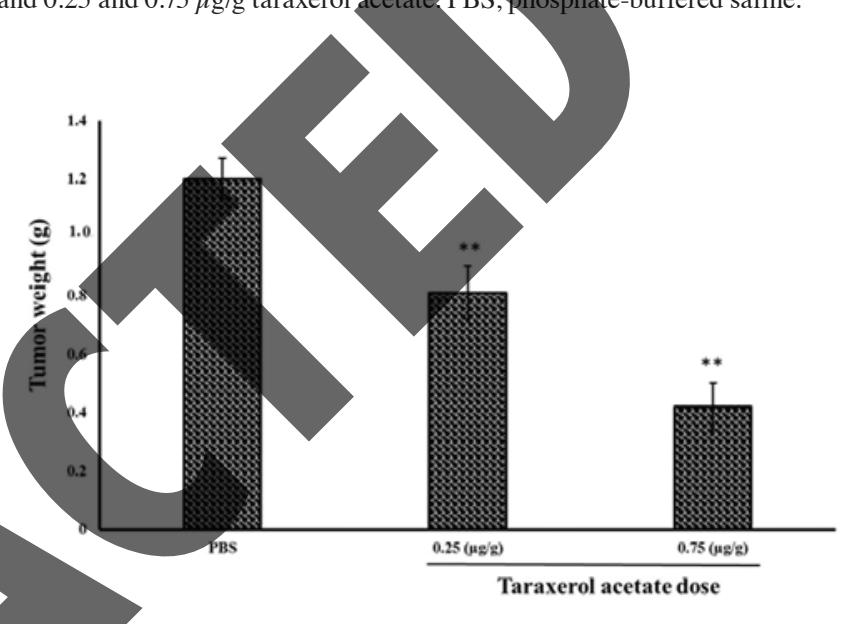

Figure 11. Tumor weight is reduced in taraxerol acetate-treated mice. Data are presented as the mean \pm standard deviation $(n=6)$. ${ }^{* *} \mathrm{P}<0.01$ vs. PBS-treated roup. PBS, phosphate-buffered saline.

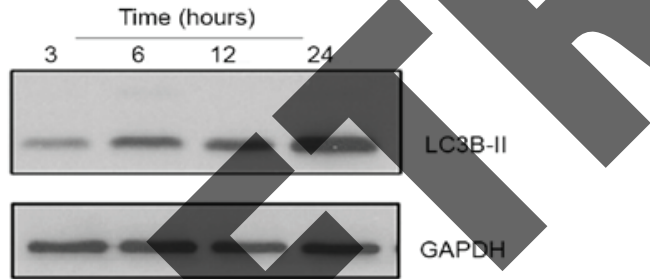

Figure 9. Taraxerol acetate induced (A) dose- and (B) time-dependent autophagy in U87 cells by upregulation of LC3B-II protein expression in these cells compared with the Cont cells. Cont, control.

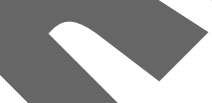

Effect of taraxerol acetate on the expression of cell cycle-associated proteins. Taraxerol acetate was demonstrated to lead to an increase in the population of sub- $\mathrm{G}_{1} \mathrm{U} 87$ cells, thus the cell cycle-regulating proteins affected by taraxerol acetate were investigated. The effect of taraxerol acetate on various cell cycle-associated proteins, including p21, cyclin B and D, CDK2, 4 and 6, was determined with western blot analysis. The results demonstrated that administration of taraxerol acetate increased the protein expression levels of the CDK inhibitor, p21 in a dose-dependent manner, compared with the control group (Fig. 8). In addition, reduced protein expression levels of cyclin B, cyclin D, CDK2, CDK4 and CDK6 were demonstrated in the taraxerol acetate-treated cells compared with the relative untreated control cells (Fig. 8).

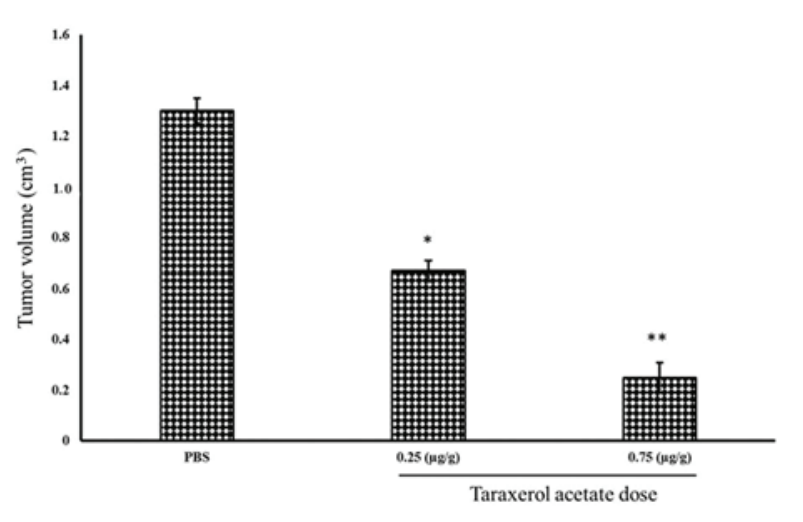

Figure 12. Taraxerol acetate treatment reduced tumor volume in the mice. Data are presented as the mean \pm standard deviation. ${ }^{* *} \mathrm{P}<0.01$ and ${ }^{\text {"P }}<0.05$ vs. PBS-treated group. PBS, phosphate-buffered saline.

Taraxerol acetate induced autophagy in the U87 cells. In addition to apoptotic cell death, taraxerol acetate induced autophagic cell death in the U87 cells. Administration of taraxerol acetate led to increased protein expression levels of LC3B-II when compared with the untreated cells (Fig. 9). The LC3B-II protein is located on the membranes of autophagosomes, which is triggered upon treatment with taraxerol acetate. The protein expression levels of LC3B-II 
increased in a dose-dependent manner (Fig. 9). In addition, the protein expression levels of LC3B-II demonstrated a time-dependence, as the expression levels increased with the increasing time intervals between 3 and $24 \mathrm{~h}$ (Fig. 9).

Taraxerol acetate reduces tumor volume and weight in $B A L B / c$ nude mice. In vitro experiments identified taraxerol acetate to be a potent cytotoxic agent, which inhibits cell proliferation, and induces apoptosis and autophagy. To determine whether taraxerol acetate induces similar anticancer effects in vivo, nude mice were treated with taraxerol acetate. Cancer was induced in the mice by injection of U87 cancer cells ( $1 \times 10^{5}$ cells/mouse). Following tumor generation, the mice were treated with 0.25 and $0.75 \mu \mathrm{g} / \mathrm{g}$ taraxerol acetate and sacrificed. Tumors were removed, and their weight and volume were measured (Fig. 10). The results demonstrate that 0.25 and $0.75 \mu \mathrm{g} / \mathrm{g}$ taraxerol acetate treatment reduced the tumor weight from $1.2 \mathrm{~g}$ in the PBS-treated group (control) to 0.81 and $0.42 \mathrm{~g}$ in the 0.25 and $0.75 \mu \mathrm{g} / \mathrm{g}$ taraxerol acetate treatment groups, respectively (Fig. 11). Similarly, 0.25 and $0.75 \mu \mathrm{g} / \mathrm{g}$ taraxerol acetate treatment reduced the tumor volume from $1.3 \mathrm{~cm}^{3}$ in the PBS-treated group (control) to 0.67 and $0.25 \mathrm{~cm}^{3}$, respectively (Fig. 12).

\section{Discussion}

Disturbance of the normal regulation of cell cycle progression and division are key events in the development and progression of cancer (19). Numerous proteins are known to regulate th timing of events in the cell cycle. Major control switches of the cell cycle are cyclins B and D, and CDK2, 4, 6. Any disturbance in these proteins results in disruption of normal cell cycle phase distribution (20). The results of the present study demonstrated that taraxerol acetate treatment led to increased protein expression levels of the CDK inhibitor, p21, and a decrease in the expression levels of cyclin B and D and CDK2, 4, 6. Furthermore, the percentage of the sub- $G_{1}$ cells increased following treatment with taraxerol acetate, and the percentage of cells in the S-phase decreased from $33.15 \%$ in the untreated cells to $27.21,16.21$ and $12.9 \%$ following 10 , 50 and $150 \mu \mathrm{M}$ taraxerol acetate treatment, respectively. Thus taraxerol acetate may be a useful chemotherapeutic agent in the treatment of various tumors. Chemotherapeutic agents that inhibit tumor growth by induction of cell cycle arrest and apoptosis are an anticipated approach in cancer therapy (21).

The apoptosis process is multifaceted and comprises of a cascade of molecular events. Two main signaling pathways, the extrinsic and the intrinsic (or mitochondrial) pathways of apoptosis, have been demonstrated (22). The intrinsic pathway is triggered by numerous stimuli, leading to a decrease in the mitochondrial transmembrane potential and subsequent release of cytochrome $c$ and pro-apoptotic effectors across the mitochondrial membrane. The final product of this signaling pathway depends on the balance between anti-and pro-apoptotic proteins, which are released from the mitochondria (23).

A variety of anti-cancer therapeutic agents have been demonstrated to arbitrate their therapeutic effect by activating apoptosis (24). The results of the present study demonstrated that taraxerol acetate treatment induced dose-dependent apoptosis, which was confirmed by fluorescence microscopy and flow cytometry. Following staining with a mixture of $\mathrm{AO}$ and EB solution, living cells $(0 \mu \mathrm{M}$; Fig. 3) were observed to possess large green nuclei, demonstrating that their cell membranes were intact. However, upon treatment with 10 , 50 or $150 \mu \mathrm{M}$ of taraxerol acetate, the number of cells with large green nuclei was markedly reduced. Flow cytometry using Annexin V-FITC as a probe demonstrated that the percentage of apoptotic cells increased from $7.3 \%$ in the control cells, to $16.1,44.1$ and $76.7 \%$ following 10,50 and $150 \mu \mathrm{M}$ taraxerol acetate treatment, respectively. In addition, taraxerol acetate treatment induced potent DNA fragmentation in a dose-dependent manner. The results of the current study demonstrated that taraxerol acetate inhibited cancer cell proliferation in vitro, and in vivo (using female BALB/c nude mice). The tumor weight and volume of cancerous tissues, which were removed from the mice, were measured. The results demonstrated that administration of 0.25 and $0.75 \mu \mathrm{g} / \mathrm{g}$ taraxerol acetate significantly reduced the tumor weight and volume when compared with the PBS-treated group.

In conclusion, the present study demonstrated that taraxerol acetate induces potent anticancer effects in U87 cells in in vitro and in vivo experiments, and these effects are mediated via the induction of apoptosis, autophagy, cell cycle arrest and inhibition of cell migration. Thus, taraxerol acetate may be a possible therapeutic agent against glioblastoma; however, further studies are required in order to decipher the exact mechanism of action and the toxicity profile of the compound.

\section{Acknowledgements}

The present study was supported by the Natural Science oundation of Fujian Province (grant no. 2011J05091).

\section{References}

1. Stupp R, van den Bent MJ and Hegi ME: Optimal role of temozolomide in the treatment of malignant gliomas. Curr Neurol Neurosci Rep 5: 198-206, 2005.

2. Wen PY and Brandes AA: Treatment of recurrent high-grade gliomas. Curr Opin Neurol 22: 657-664, 2009.

3. Louis DN, Ohgaki H, Wiestler OD, Cavenee WK, Burger PC, Jouvet A, Scheithauer BW and Kleihues P: The 2007 WHO classification of tumours of the central nervous system. Acta Neuropathol 114: 97-109, 2007.

4. Kieran MW, Walker D, Frappaz D and Prados P: Brain tumors: From childhood through adolescence into adulthood. J Clin Oncol 28: 4783-4789, 2010.

5. Zhou LF, Wang RZ and Bao SD: Chinese guideline for diagnosis and treatment on central nervous system tumors. (In Chinese) Zhonghua Yi Xue Za Zhi 92: 2309-2313, 2012.

6. Chang L, Su J, Jia X and Ren H: Treating malignant glioma in Chinese patients: Update on temozolomide. Onco Targets Ther 7: 235-244, 2014

7. Yang P, Wang Y, Peng X, You G, Zhang W, Yan W, Bao Z, Wang Y, Qiu X and Jiang T: Management and survival rates in patients with glioma in China (2004-2010): A retrospective study from a single-institution. J Neurooncol 113: 259-266, 2013.

8. Chen C, Xu T, Lu Y, Chen J and Wu S: The efficacy of temozolomide for recurrent glioblastoma multiforme. Eur J Neurol 20: 223-230, 2013.

9. Wang $J$ and and Jiang YF: Natural compounds as anticancer agents: Experimental evidence. World J Exp Med 2: 45-57: 2012.

10. Fujii $\mathrm{T}$ and Saito $\mathrm{M}$ : Inhibitory effect of quercetin isolated from rose hip (Rosa canina L.) against melanogenesis by mouse melanoma cells. Biosci Biotechnol Biochem 73: 1989-1993, 2009.

11. Kornienko A and Evidente A: Chemistry, biology, and medicinal potential of narciclasine and its congeners. Chem Rev 108: 1982-2014, 2008. 
12. Ulbricht CE and Chao W: Phytochemicals in the oncology setting. Curr Treat Options Oncol 11: 95-106, 2010.

13. Surh YJ: Cancer chemoprevention with dietary phytochemicals. Nat Rev Cancer 3: 768-780, 2003.

14. Perry MC, Demeule M, Régina A, Moumdjian R and Béliveau R: Curcumin inhibits tumor growth and angiogenesis in glioblastoma xenografts. Mol Nutr Food Res 54: 1192-1201, 2010.

15. Turbyville TJ, Gürsel DB, Tuskan RG, Walrath JC, Lipschultz CA, Lockett SJ, Wiemer DF, Beutler JA and Reilly KM: Schweinfurthin A selectively inhibits proliferation and Rho signaling in glioma and neurofibromatosis type 1 tumor cells in a NF1-GRD-dependent manner. Mol Cancer Ther 9: 1234-1243, 2010.

16. Filippi-Chiela EC, Villodre ES, Zamin LL and Lenz G: Autophagy interplay with apoptosis and cell cycle regulation in the growth inhibiting effect of resveratrol in glioma cells. PLoS One 6: e20849, 2011.

17. Liang CC, Park AY and Guan JL: In vitro scratch assay: A convenient and inexpensive method for analysis of cell migration in vitro. Nat Protoc 2: 329-333, 2007.
18. Kim A, Im M, Yim NH, Kim T and Ma JY: A novel herbal medicine, KIOM-C, induces autophagic and apoptotic cell death mediated by activation of JNK and reactive oxygen species in HT1080 human fibrosarcoma cells. PLoS One 9: e98703, 2014.

19. Sandal T: Molecular aspects of the mammalian cell cycle and cancer. Oncologist 7: 73-81, 2002.

20. Santos SDM and Ferrell JE: Systems biology: On the cell cycle and its switches. Nature 454: 288-289, 2008.

21. Schultz DR and Harrington WJ Jr: Apoptosis: Programmed cell death at a molecular level. Semin Arthritis Rheum 32: 345-369, 2003.

22. Elmore S: Apoptosis: A review of programmed cell death. Toxicol Pathol 35: 495-516, 2007.

23. Hayakawa S, Saeki K, Sazuka M, Suzuki Y, Shoji Y, Ohta T, Kaji K, Yuo A and Isemura M: Apoptosis induction by epigallocatechin gallate involves its binding to Fas. Biochem Biophys Res Commun 285: 1102-1106, 2001.

24. Los M, Burek CJ, Stroh C, Benedyk K, Hug H and Mackiewicz A Anticancer drugs of tomorrow. Apoptotic pathways as targets for drug design. Drug Discov Today 8: 67-77, 2003.

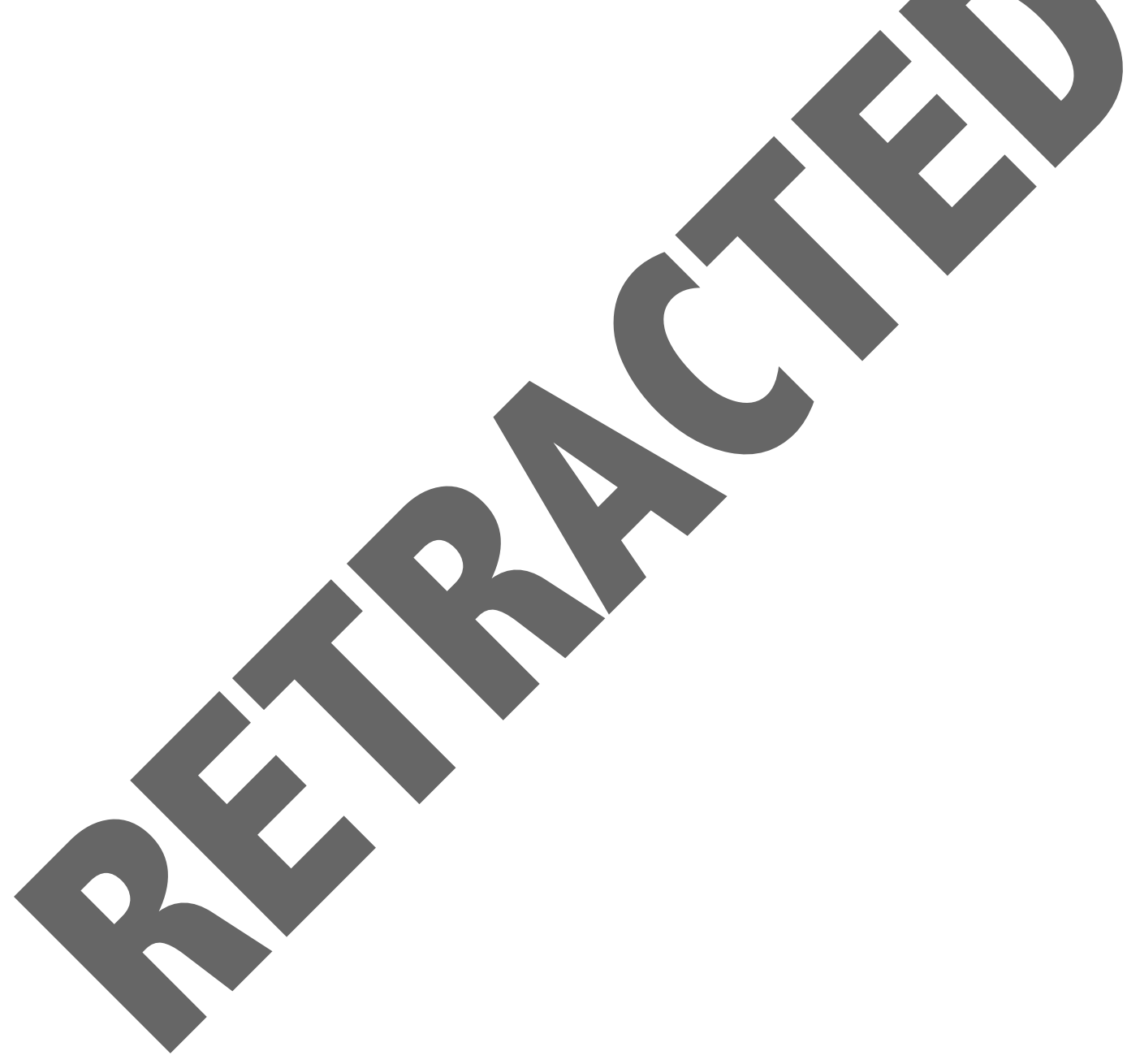

